\title{
Novel Target Configurations for Selective Ionization State Studies in Molybdenum
}

\author{
K.J. Ilcisin, U. Feldman ${ }^{*}$, J.L. Schwob ${ }^{\dagger}$ A. Wouters, and S. Suckewer ${ }^{¥}$, \\ Princeton Plasma Physics Laboratory, \\ Princeton University \\ Princeton NJ 08543 \\ DE9 $0 \quad 008231$
}

\begin{abstract}
Details of experiments aimed at achieving low ionization state selectivity in molybdenum are presented. Targets are excited with a $10 \mathrm{~J} \mathrm{CO}_{2}$ laser and the resultant VUV spectrum ( $300-700 \AA)$ has been studied. Combinations of focal spot size, target depth, and target geometries are compared. Simple attenuation of energy is shown not to vary ionization stage composition significantly. Experiments conducted with grazing incidence targets result only in a hot plasma. Modular targets with cooling cylinders of various radii demonstrated good selectivity of the ionization states, but with low absolute signals. Finally, results from combinations of focal spot adjustment and radiative cooling illustrate increased control over desired plasma temperature and density for spectroscopic studies of molybdenum.
\end{abstract}

* Permanent Address; E. O. Hulbert Center for Space Research, Naval, Research Laboratory, Washington, D. C.

$\dagger$ Permanent Address; Racah Institute of Physics, Hebrew University of Jerusalem, Jerusalem, Israe!.

$¥$ Also Mechanical and Aerospace Engineering Department 


\section{Introduction}

Plasma Spectroscopy is both an important diagnostic tool, being used to measure impurity concentrations and ion temperature, and as an aid in understanding basic atomic processes. Laser research has relied heavily on the proper identification of potential lasing transitions. This work describes experimental techniques used to generate molybdenum plasmas suitable for studying transitions for Mo V-Mo XIV. Also, recent discrepancies ${ }^{1,2}$ in line identification for Mo VII ions prompted an independent verification of the VUV transistions for the $300-700 \AA$ region using a laser produced plasma. The results of this study agree with the new identification given by Reader and Feldman. ${ }^{1}$ A proposed scheme for an $x$-ray laser ${ }^{3}$ using multiphoton processes to achieve doubly excited transititions in $\mathrm{Kr}$ I like Mo VII requires control over the density and temperature of a molybdenum plasma. This data will be used as a basis tor describing the heating and cooling of partially stripped high $\mathrm{Z}$ plasmas

\section{Experimental Arrangement}

Figure 1 shows the setup used for these experiments. The laser was a commercial 10 Joule 150 ns $5 \mathrm{WHM} \mathrm{CO} \mathrm{CO}_{2}$ laser operated in an unstable resonator configuration. The laser output was focused with a single $50 \mathrm{~cm}$ spherical lens. Line focus experiments were performed with the insertion of a hand ground negative curvature optic. The targets were made up of components of pure Mo $(99.9 \%)$. Crater damage after hundreds of shots showed less than $0.5 \mathrm{~mm}$ penetration. The target position was changed aftcr every ten shots to ensure surface consistency from shoi to shot. At every new position several cleaning shots were taken to remove oxide layers before taking spectra. The spectra were recorded with a McPherson $1.5 \mathrm{~m}$ grazing incidence spectrometer modified to take a multi channel plate (MCP) and a 1024 pixel detector giving a time integrated measurement. The 600 lines/mm holographic grating is very efficient in second order and thus extended the 
lower limit of the range from $300 \AA$ to $150 \AA$. Our data acquisition system is Macintosh based and has been described in detail elsewhere. 4

\section{Experimental Results:}

\section{Energy Attenuation}

Varjing the input energy was expected to allow selectivity of ionization stages of molybdenum. The input energy was changed by inserting various thicknesses of teflon in the beam path. An absorption coefficient for teflon at $10.6 \mu \mathrm{m}$ was measured to be $5.9 / \mathrm{mm}$ using a calibrated beam splitter and calorimeter arrangement. Figure 2 shows a typical spectrum centered around $650 \AA$ for a full beam shot $(10 \mathrm{~J})$ and a shot with $0.254 \mathrm{~mm}$ of teflon inserted $(2.2 \mathrm{~J})$. Although there is a slight increase in the relative intensity of the lower stages of ionization, the primary effect of reducing the input energy is a decrease in absolute intensity of the entire spectrum. This prevents this approach from being a means of generating the cooler plasmas we wanted to study. Furthermore, overlap between 2nd order Mo X, and Mo XI lines made the verification of the Mo VII lines impossible. At energies below $1 \mathrm{~J}$ (teflon thickness greater than $0.38 \mathrm{~mm}$ ) no spectra were observed.

\section{Grazing Incidence Targets}

In these experiments, the effects of line focus were to be mimicked by having the target struck at angles of $30^{\circ}$ and $10^{\circ}$ giving a 2.5 and 8 times reduction in the power density while maintaining total energy deposited. Figure 3 shows the geometry used in these experiments. Care was taken to avoid reflections or interactions of the expanding plasma with surrounding surfaces. These target configurations did not provide any cooling of the plasma. The spectra resulting from these angled targets were identical to those produced with a normal incidence arrangement. Our explanation, ror this effect, is that although the initial power density on the solid target is reduced, the plasma expands into the direct focus of the laser. Ai these plasma 
temperatures, classical inverse bremsstrahlung absorption is expected to be greater than $80 \% .5,6$ This would drive a heating wave which would penetrate the entire plasma length.

\section{Modular Target Experiments}

The purpoze of these targets was to effect the cooling of the plasma through interaction with the walls of a cylinder composed of target material. This simultaneously prevents the sharp decreases in density characteristic of free expansion. A modular design was used which permitted quick changes in target geometry while preserving alignment. Figure 4 shows a typical target makeup. The laser is normally incident on a stack of molybdenum plates (1$2.5 \mathrm{~mm}$ thick ). Each plate has either a hole, of various radii , drilled through it, or a rectangular hole with a knife edge in the middle. In all targets, the bottom three pieces in the base formed a spacer which defines the alignment of the target with the spectrometer. In addition, the bottom piece was used to reflect stray plasma and laser light away from the field of view of the spectrometer. These three pieces were used in all target configurations. Later refererices to a target configuration will describe only the pieces that are stacked on top of the bottom three.

Combinations which had cylinders of various radii and length stacked together did not result in any significant cooling of the plasma. Length of a cylinder is defined by the thickness of the plate the hole was drilled through. However, the combination of a cooling cylinder and a knife edge piece did reduce the plasma temperature. Figure 5 shows the results for a $1 \mathrm{~mm}$ wide knife edge stacked below a $2.5 \mathrm{~mm}$ long $1.5 \mathrm{~mm}$ radius cooling cylinder. Figures $5 \mathrm{a}$ and $5 \mathrm{~b}$ show that the spectra obtained when the knife edge is stacked above the alignment pieces alone ( $5 \mathrm{a}$ ) and when a $2.5 \mathrm{~mm}$ long cooling cylinder is placed between the alignment pieces and the knife edge (5b) were similar. These spectra are similar to that for a slab target. These figures show that the small difference in position of the knife edge above the alignment pieces ( and hence the focal spot size at the knife edge) does not dramatically affect the resultant plasma. In addition, in this configuration the 
1.5 mun radius cooling cylinder does not have any effect on the plasma. Figure $5 \mathrm{c}$ shows the result when the previously mentioned cooling cylinder is placed above the knife edge. This target was checked for any direct inieraction between the incident beam and the sides of the cylinder. There is no clipping of the beam by the cylinder. Thus the observed decrease in plasma temperature was not due to any aperaturing of the beam. The lower temperature plasma that is seen (i.e., the observed spectrum included lines of Mo V and Mo VI only) is due to a plasma shutter. The higher density maintained in the volume of the cooling cylinder is suspected of producing a plasma shutter that reduces the resultant temperature of the observed plasma.

\section{Expansion Cooling}

Figure 6 details the arrangement used to study the effect of free expansion on the plasma temperature and density. The laser was point focused normally incident on a planar target. A $1 \mathrm{~mm}$ slot in a mask could be positioned at any height above and parallel to the target. The spectrograph slit is behind and parallel to the slot. The plasma was sudied for mask positions $0-4 \mathrm{~mm}$ above the target surface in $1 \mathrm{~mm}$ increments. Above $4 \mathrm{~mm}$ signal levels are sufficiently small as to place a limit of $5 \mathrm{~mm}$ on the spatial extent of the plasma. This differs from previously reported results 6 for Carbon where reasonable signals were obtained up to $10 \mathrm{~mm}$ above the target surface. Figures 7-9 show representative spectra for molybdenum targets near 320 , 410 , and $650 \AA$, respectively. In each figure, the dominant lines are identified, blends are indicated by a dual assignment. Spectra are shown for all wavelength regions for the mask a) at the target surface, b) $2 \mathrm{~mm}$ above the target surface, and c) $4 \mathrm{~mm}$ above the surface. The conclusions from these spectra are best summarized with figs. $10 \mathrm{a}, \mathrm{b}$. Figure $10 \mathrm{a}$ is a plot of the average intensity for several ionization states. This is calculated by averaging the intensities of lines from a specific charge state that were free of blends at any mask position, and of comparable intensity. There was only one slean line for both Mo VIII and MoXIV so these intereities are plotted directly. The key point from this figure is that there is a frozen temperature profile associated 
with this type of cooling. Although the absolute intensities of all the lines decreased due to the density decrease, the relative intensities remained constant. The drop in density can be inferred from fig. 10b which is a plot of the background intensity (continuum radiation) with distance above the target for the point focus. As the bremsstrahlung emissivity scales as $\left(n_{e}\right)^{2} T_{e}{ }^{-1 / 2}$ this motivates the strong density dependence of our intensities.

\section{Expansion Cooling With Beam Defocussing}

As shown in the preceding section, simple txpansion cooling could not effectively generate cold molybdenum plasmas because of the fast decrease in electron temperature and Mo densities. By placing a salt flat, with hand ground negative curvature in one axial direction, we were able to expand our $200 \mu \mathrm{m}$ focal spot size to a line measuring 2.5 by $13 \mathrm{~mm}$. The resulting power density at normal incidence on a planar target $\left(1.5 \cdot 10^{8} \mathrm{~W} / \mathrm{cm}^{2}\right)$ gives a controllable, predominately cold, plasma at a distance greater than $1 \mathrm{~mm}$ above the target surface. Figures 11-13 for the line focus correspond to those in figs. 7-9 for the point focus. In these figures, the key point is that the charge state balance does change significantly with the distance above the target. The extent of the plasma is the same as for the point focus case, approximately 5 $\mathrm{mm}$. Figures 11a-13a show the dominance in intensity of Mo X-XIV. Figures $11 \mathrm{~b}-13 \mathrm{~b}$ show that $2 \mathrm{~mm}$ above the target surface, the intensities of the hot molybdenum transitions ( Mo XI - Mo XIV) are much smaller than those of the colder ions. The final group of figures at $4 \mathrm{~mm}$ show that the hot transitions are nonexistent. Figure $14 \mathrm{a}$ is the plot of the average line intensities versus distance for the line focus. Here it is clearly seen that over the same $5 \mathrm{~mm}$ spatial extent as covered in the point focus experiments, the dominant charge states range from the hot Mo XI-XIV to a mixture of Mo VVIII. Figure $14 \mathrm{~b}$ again is the curve of backgrourid intensity for the line focus. It shows a slightly slower drop off in density. This can be attributed to the expected cylindrically symmetric expansion resulting from the line geometry of these plasmas as compared to the spherical expansion for a plasma created by the point source. These spectra, when examined specifically for line identification of Mo VII, show agreement with the recent results of Reader \& Feldman. ${ }^{1}$ Further examination of the target surface indicated the existence 
of hot spots. These likely contributed significantly to the intensity of the observed high ionization states. Intentionally blocking the portion of the beam that was suspected of producing the hot spots reduced the intensities of the hot molybdenum ions to almost zero. Better spatial control over the beam should reduce the creation of the hot ions thus reducing the observed intensities of these ions even further.

\section{Conclusions}

Through a proper selection of laser power density, and position above the target surface, we have achieved control over the temperature and density of a molybdenum plasma. We have generated both cold plasmas, where the dominant ionization stages are Mo V-Mo VIII, and hot plasmas, where Mo X is the lowest ionization state seen. Ranges between these two have also been observed but have not been presented here. Spectroscopic analysis of the cold plasma, concentrating on Mo VII, has confinmed the new line identification of Reader and Feldman. ${ }^{1}$ The spatial extent of these plasmas $(-5 \mathrm{~mm})$ is significantly smaller than that of lower $Z$ elements.

\section{Acknowledgements}

The authors would like to express their thanks to a number of people who have greatly enhanced the progress of this work. Thanks goes to Dr. Y. Chung who developed the data aquisition system used in the lab; Dr. F. Aumayr for his help in running and analyzing the data; Drs. E. Valeo and B. Tighe for there helpful discussions on $\mathrm{CO}_{2}$ laser heating of a plasma. $\mathrm{G}$. Drozd, A Schuessler, J. Schwarzmann, and D. DiCicco are to be thanked for their skill in machining the various molybdenum targets. We are grateful for L. Meixler and N. Tkach's expert help with our signal and noise problems as well as for their help in rebuilding the laser. This work was supporied by the U.S. Department of Energy, Advanced Energy Projects Contract No. KC-0501, and one of the authors (K.I.) is thankful for continued support by the Natural Sciences and Engineering Research Council of Canada. 


\section{Beferences}

1 Joseph Reader, and Uri Feldman, ( submitted to J. Opt. Soc. Am. B. )

2A. Tauheed and M.S.Z. Chaghtai, J. Phys. B 17, 179 ( 1984 )

3C.W. Clark et al., J. Opt. Soc. Am B 3, 371 ( 1986.)

4Y. J. Chung, Ph.D. Thesis, Princeton University, ( 1989 )

5J.P. Anthes, M.A. Palmer, M.A. Gusinow, \& M.K. Matzen, Appl, Phys. Lett., 34, 841 ( 1979 )

${ }^{6}$ A. Montes, M. Hubbard, C. Kler, \& IJ. Spalding, Appl. F'hys. Lett., 36, 652 (1980)

${ }^{7}$ C. J. Keane, Ph.D. Thesis, Princeton University, ( 1986 ) 


\section{Eipure Captions}

Figure 1. Experimental Arrangement.

Figure 2. Molybdenum spectra near $650 \AA$. a) Spectrum for full beam ( $10 \mathrm{~J}$ ), b) Spectrum with $0.010^{\prime \prime}$ teflon insered (2.2J).

Figure 3. Target Arrangenent for the grazing incidence experiments.

Figure 4. Composition of the modular taryots a) cross sectional view, b) perspective as seen with the laser impinging on the top plate.

Figure 5. Spestra near $650 \AA$ for the modular molybdenum target.

Figure 6. Arrangement for Expansion Cooling Experiments.

Figure 7. Spectrum for a $200 \mu$ point focus on a planar target near $320 \AA$.

Figure 8. Spectrum for a $200 \mu$ point focus on a planar target near $410 \AA$.

Figure 9. Spectrum for a $200 \mu$ point focus on a planar target near $650 \AA$.

Figure 10. a) Line intensitites vs distance for the $200 \mu$ point focus, b) background intensity vs distance for the point focus.

Figure 11. Spectrum for a line focus on a planar target near $320 \AA$.

Figure 12. Spectrum for a line focus on a planar target near $410 \AA$.

Figure 13. Spectrum for a line focus on a planar target near $650 \AA$

Figure 14. a) Line intensities vs distance for the line focus, b) Background intensity vs distance for the line focus. 


\section{Experimental Setup}

Target

chamber

$\mathrm{CO}_{2}$ Laser
$10 \mathrm{~J} 150 \mathrm{~ns}$
FWHM

$50 \mathrm{~cm}$

Focusing iens
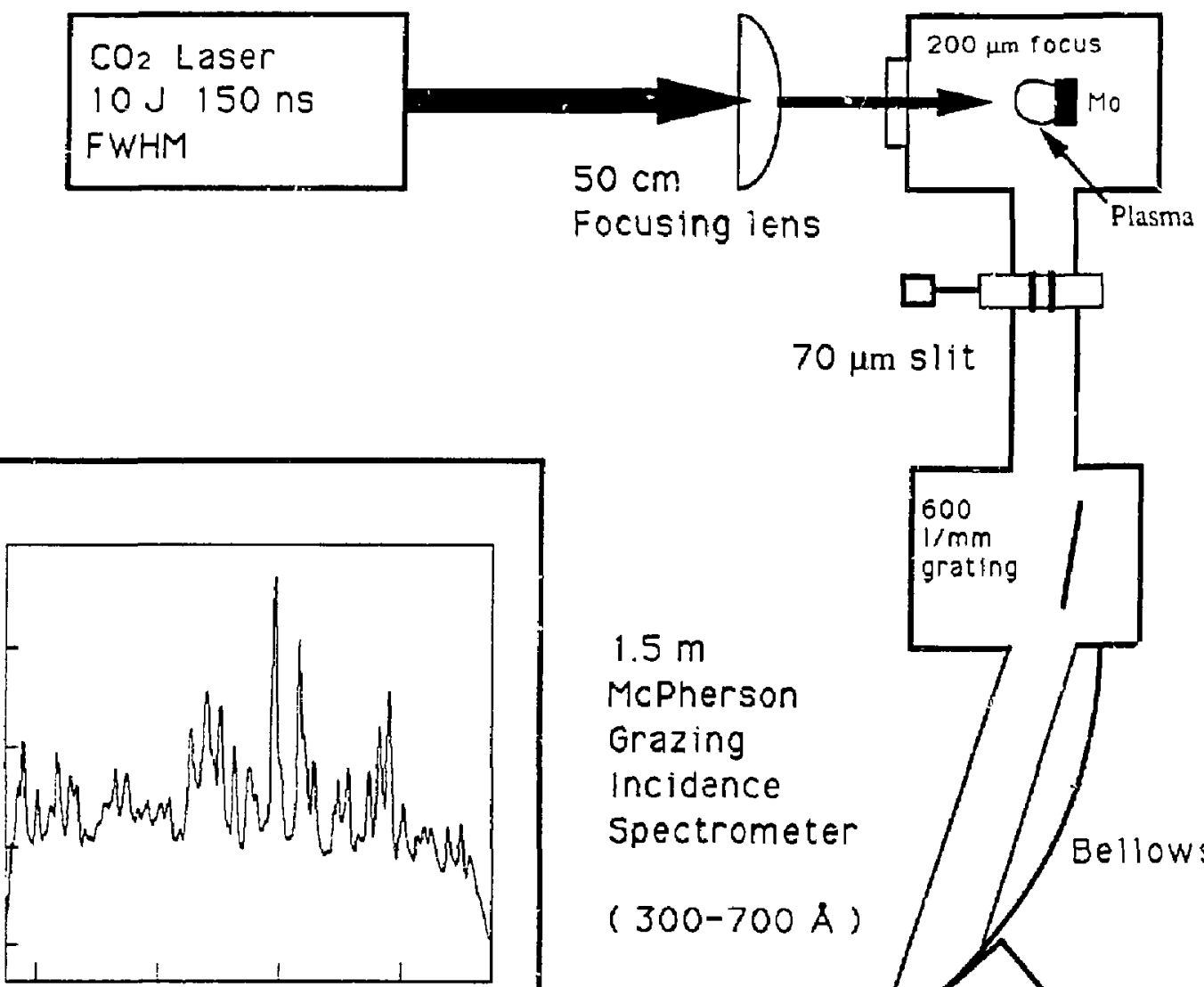

$1.5 \mathrm{~m}$

McPherson

Grazing Incidance

Spectrometer

$(300-700 \AA)$

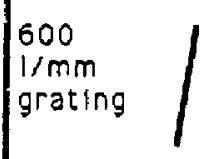

Macintosh Based Data Aquisition System

\section{Fig. 1}

Detector on

Roland Circie

MCP Detector 


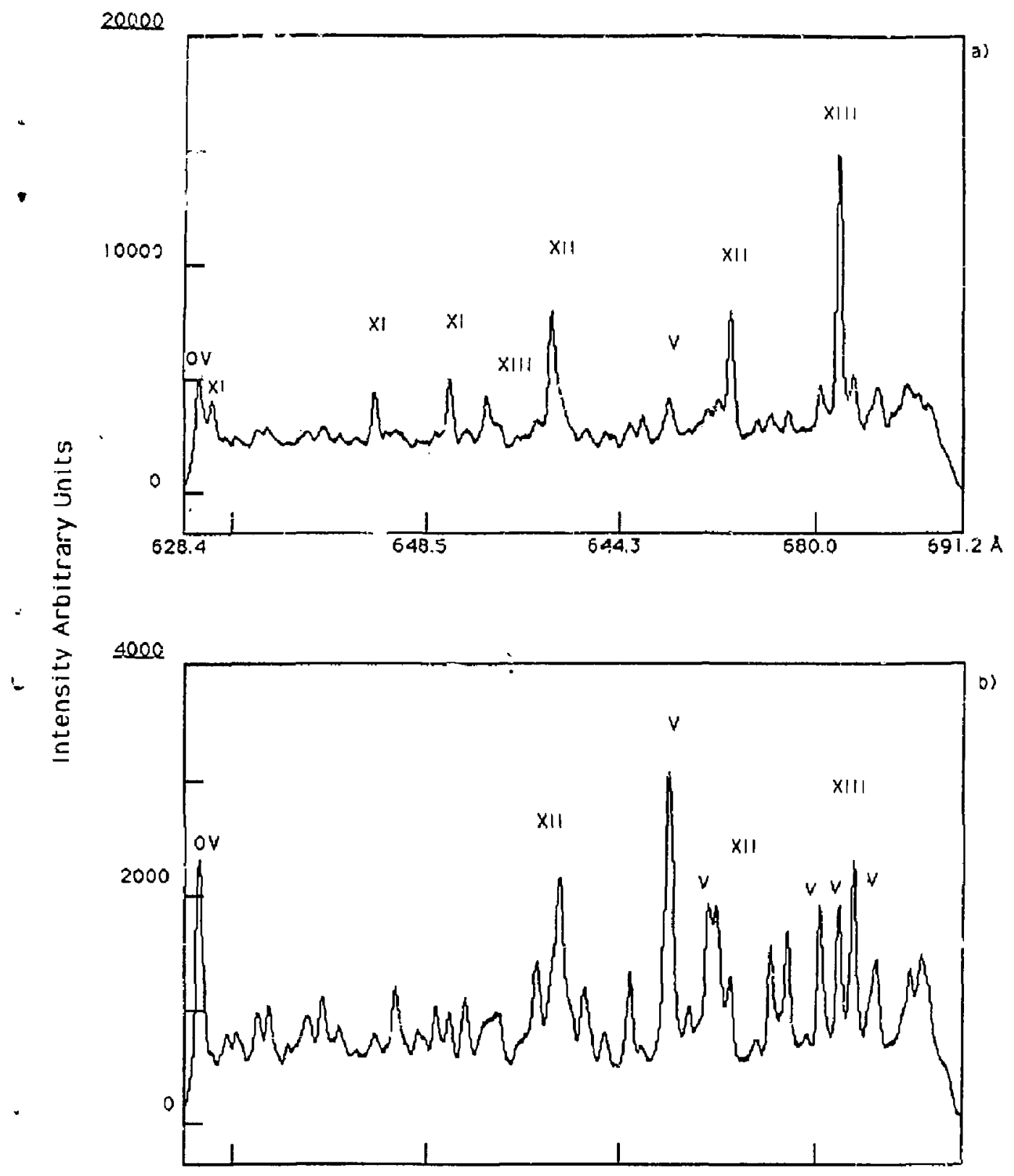

Fig. 2 


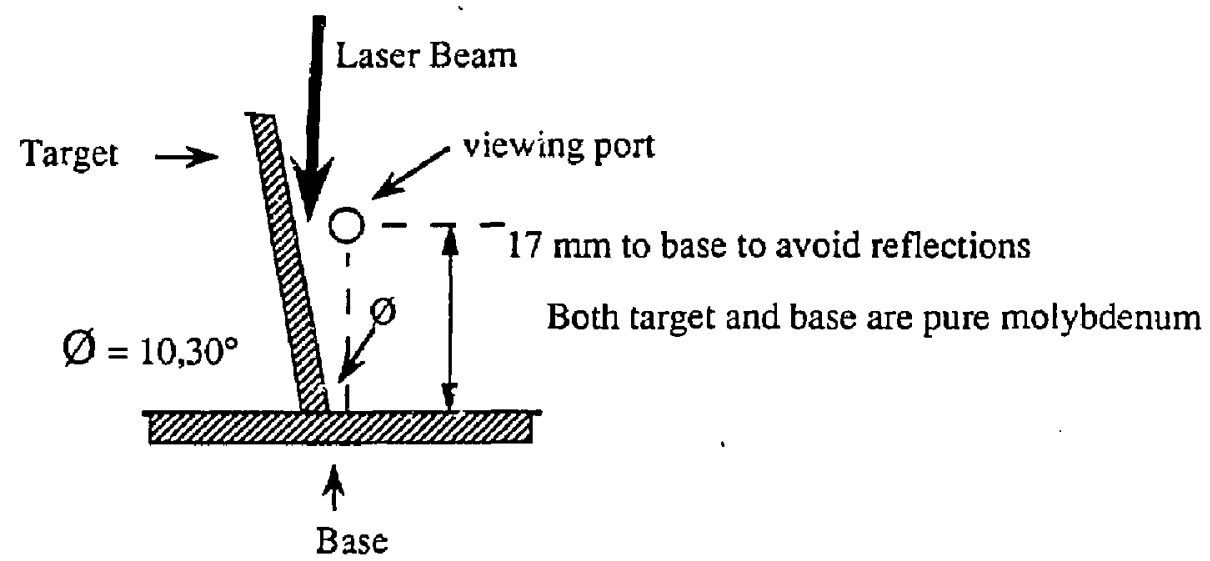

Fig. 3 
a)

spectrometer

$\measuredangle$

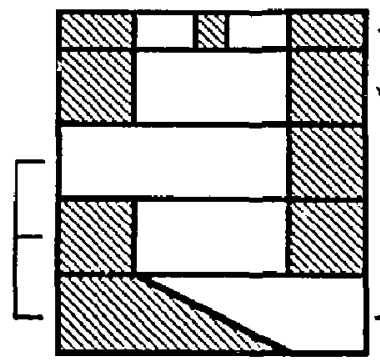

* imm thick knife edge

Viewing plece

$2.5 \mathrm{~mm}$ : $\mathrm{nlck}$

Bottom pieces used

for all experiments

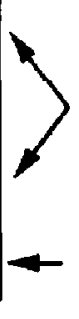

$3 \mathrm{~mm}$ dia cooling cylinder $25 \mathrm{~mm}$ thick

wedge $25 \mathrm{~mm}$ thick to reflect - Piasma and Laser away from spectrometer view

D)

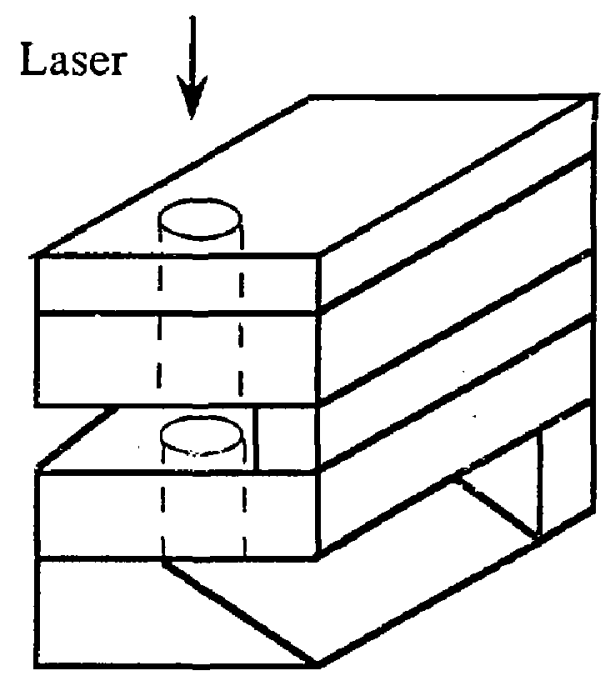

Fig. 4 


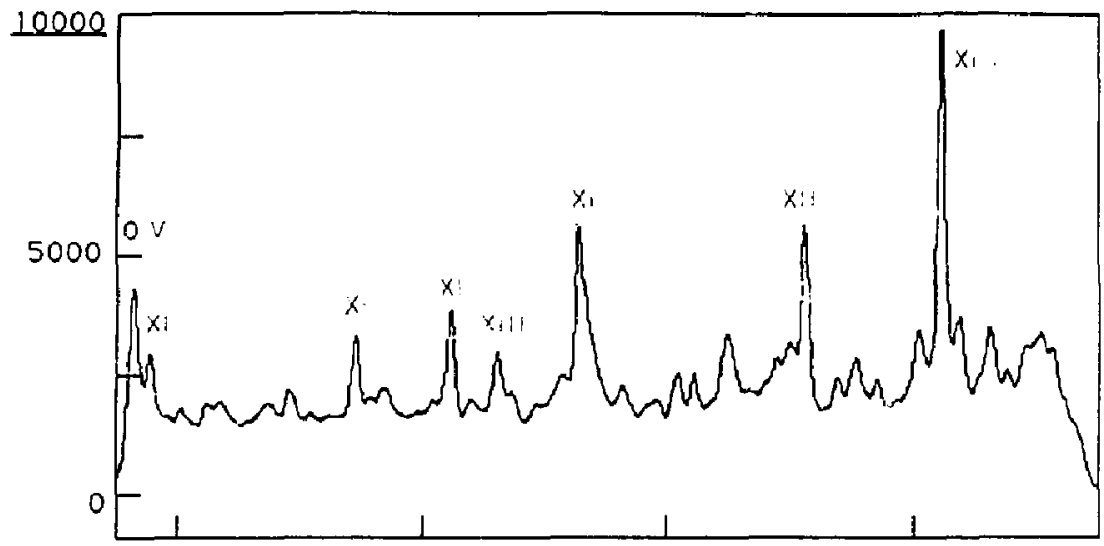

Q 11

a) knife edge only

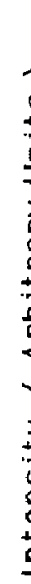

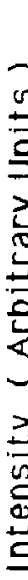

10000

D:

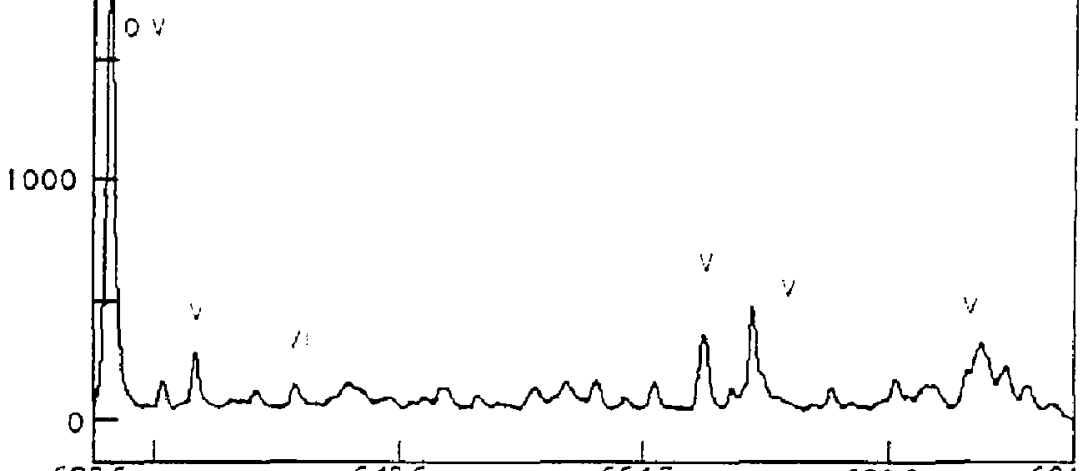

$\begin{array}{lllll}628.6 & 648.6 & 564.5 & 580.2 & 591.6 \text { A }\end{array}$

Fig. 5 


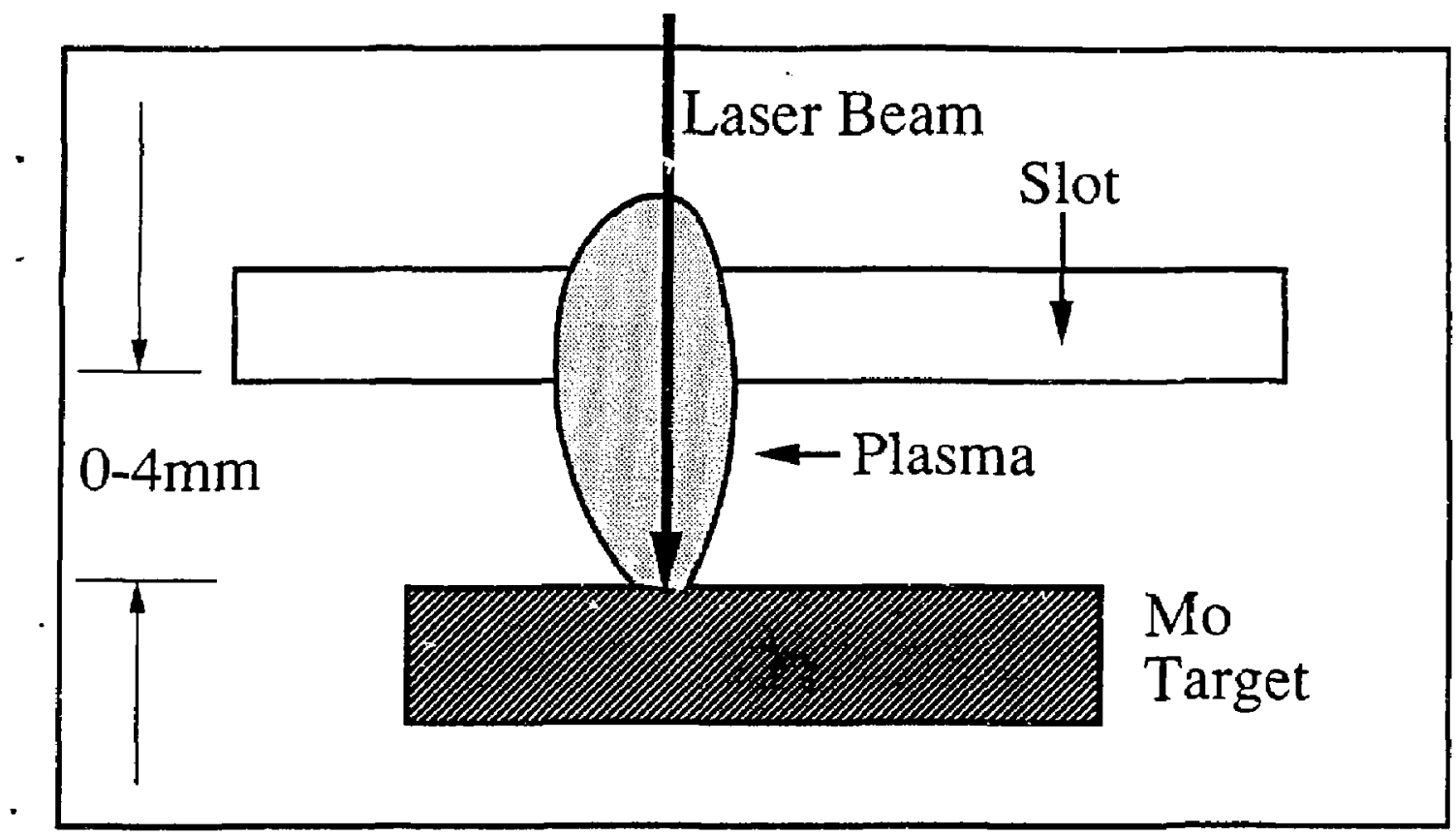

Fig. 6 
a) At target surface
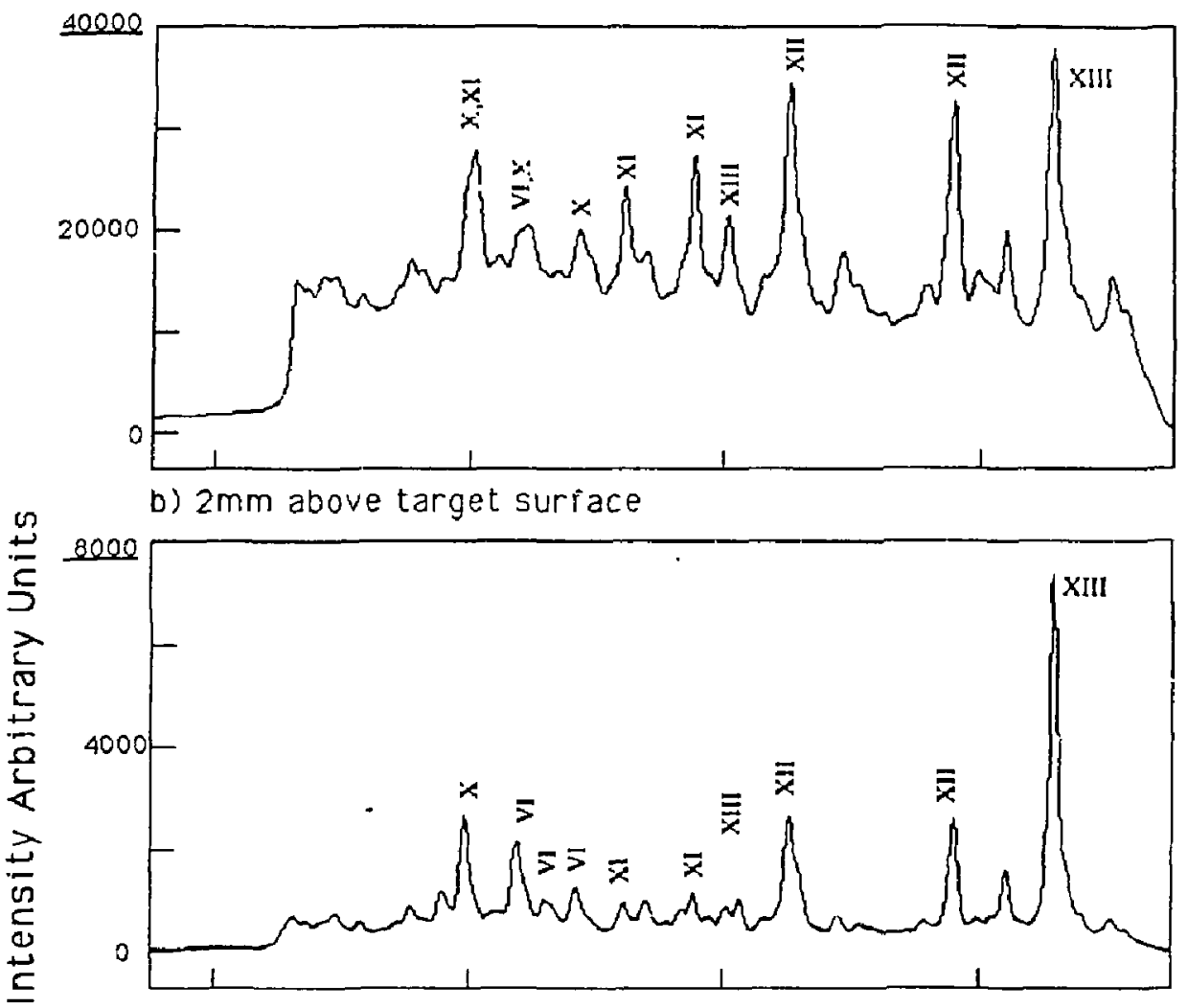

c) $4 \mathrm{~mm}$ above target surface

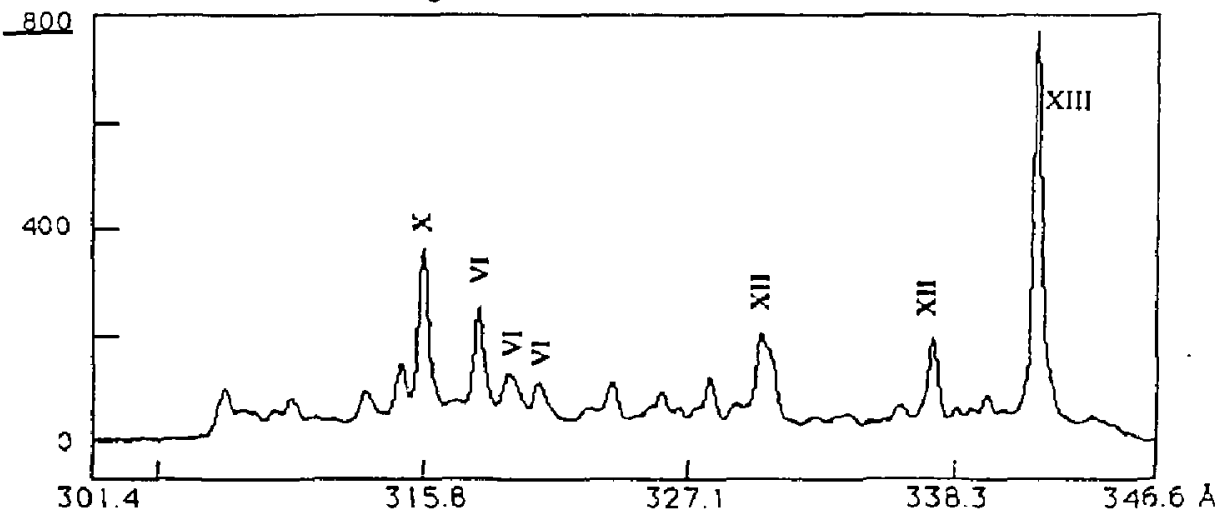

Fig. 7 
a) At target surface
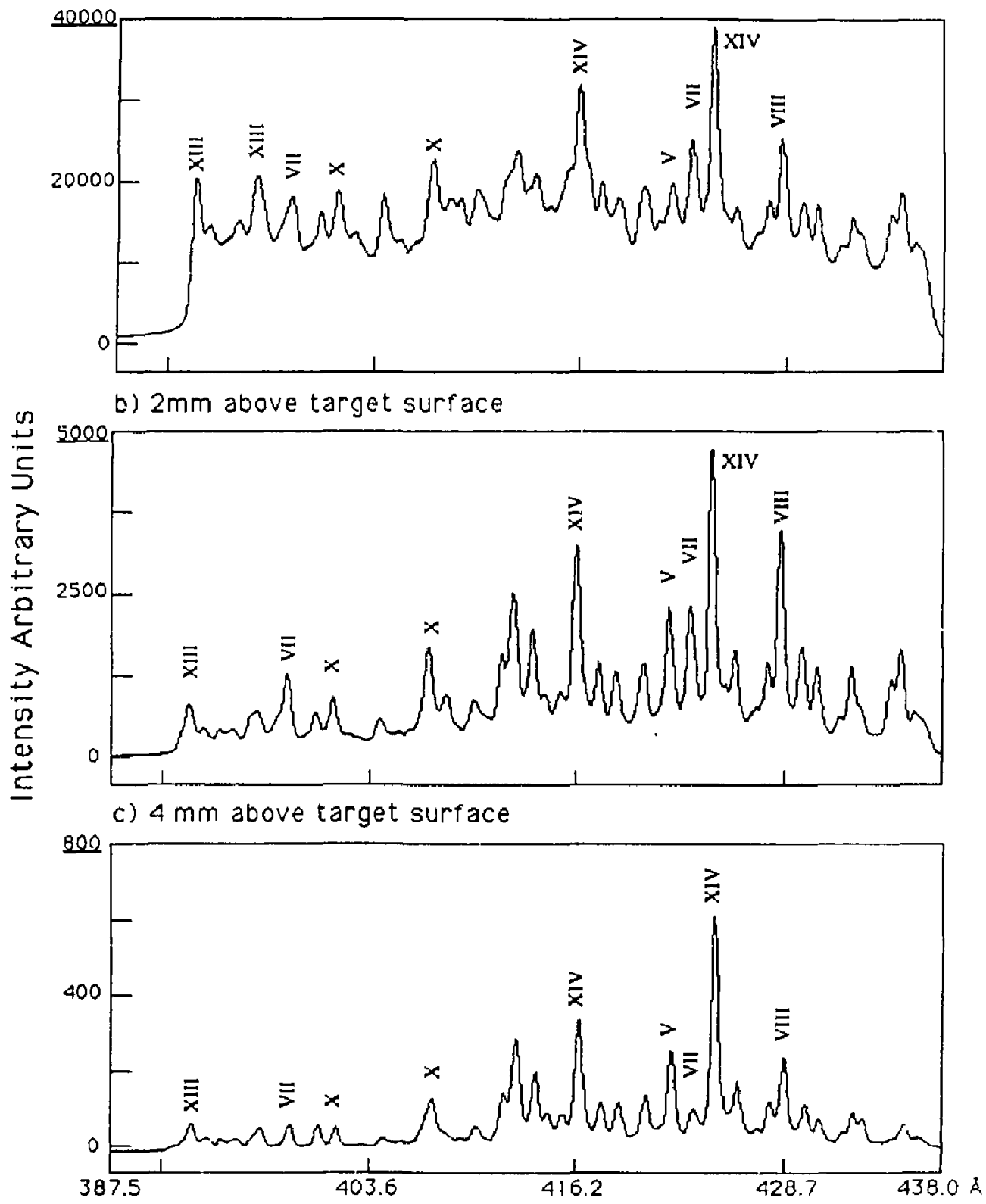

Fig. 8 
a) At target surface
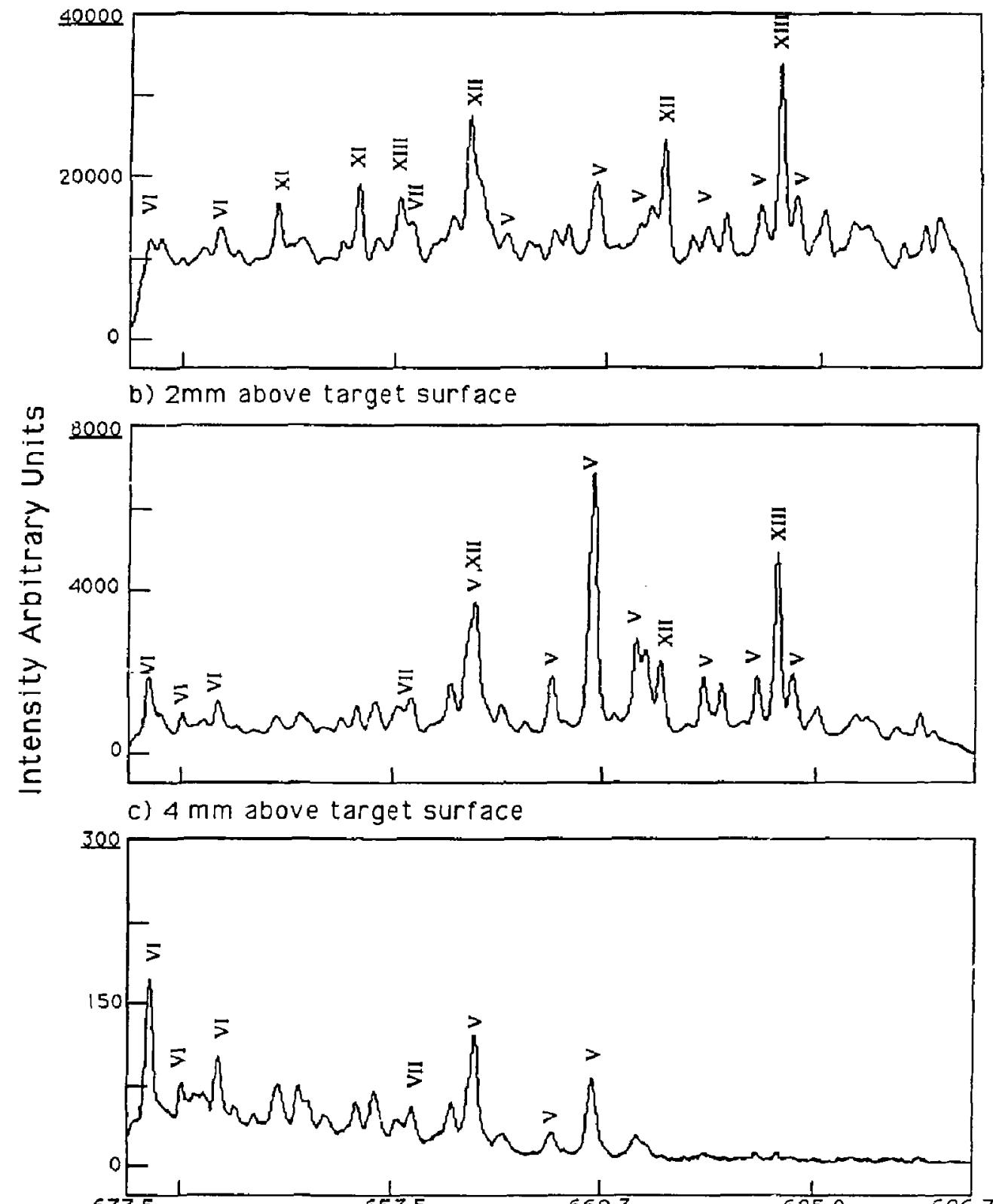

633.5

653.5

669.3

$696.7 \AA$

Fig. 9 


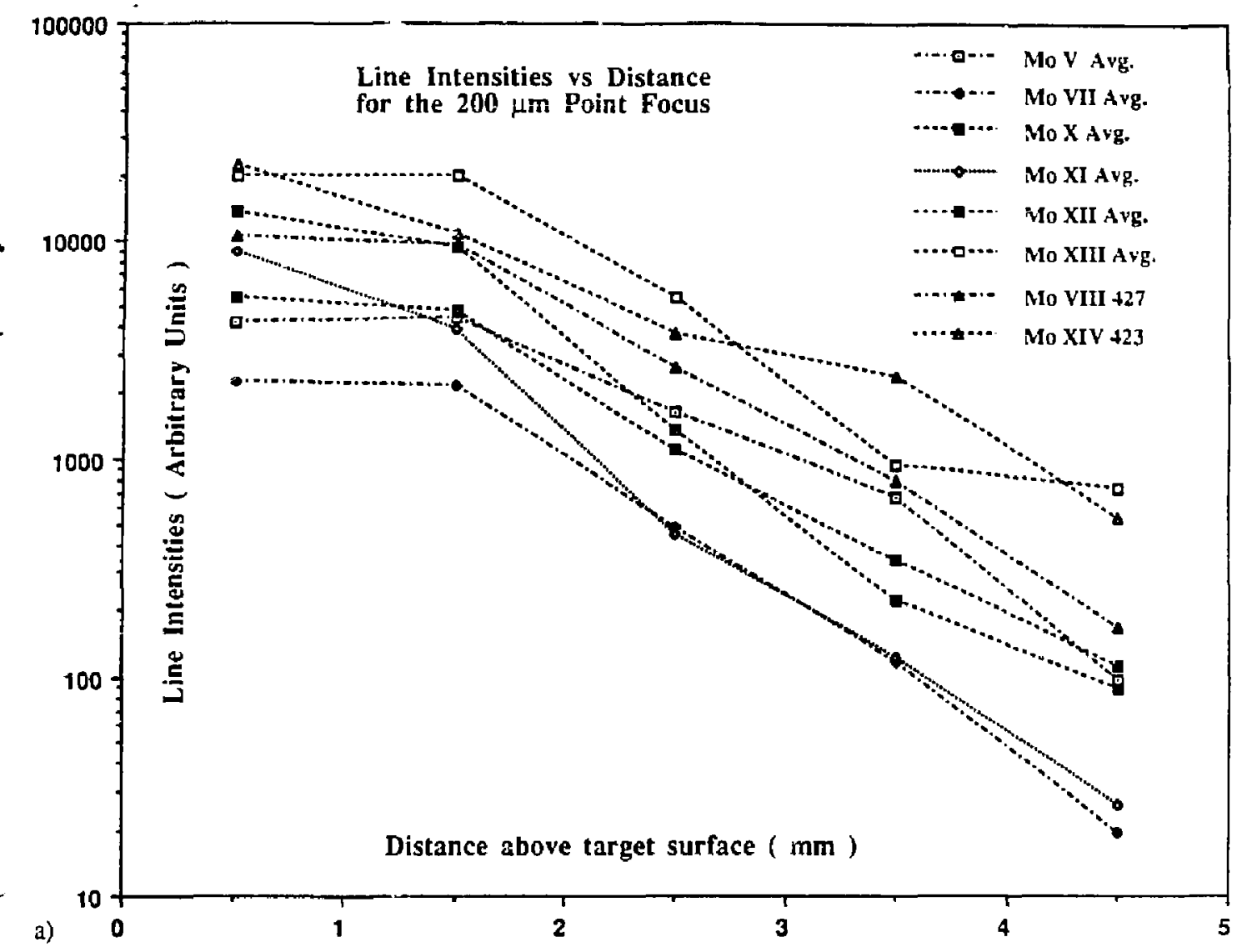

Background Intensity vs Distance for the Point Focus

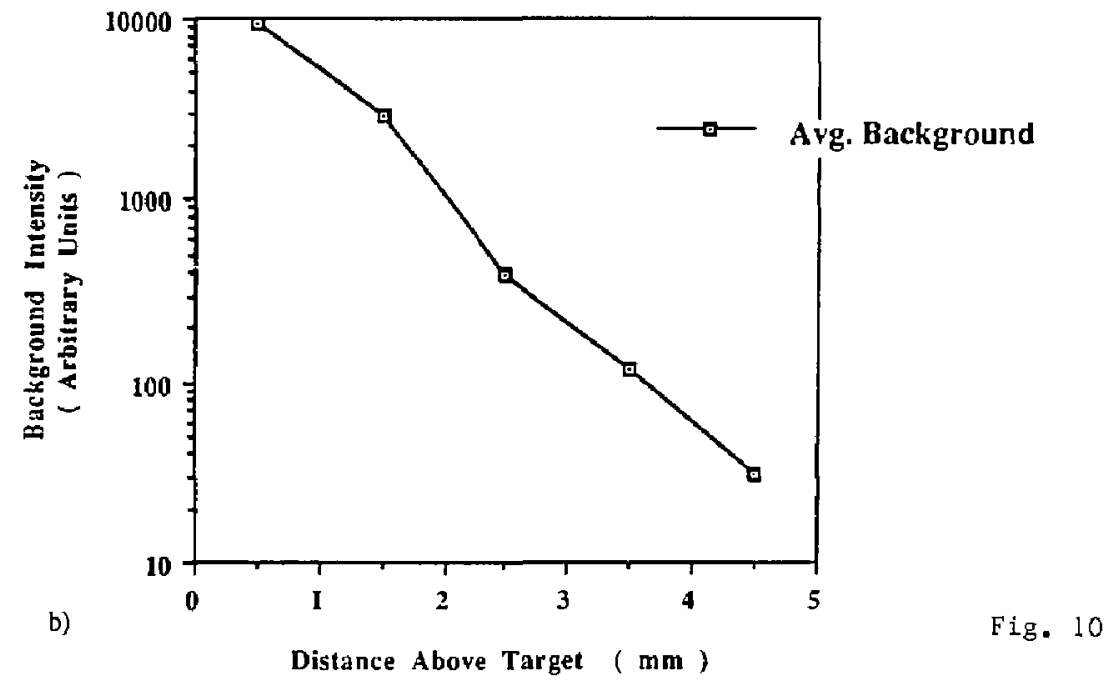


a) At target surface

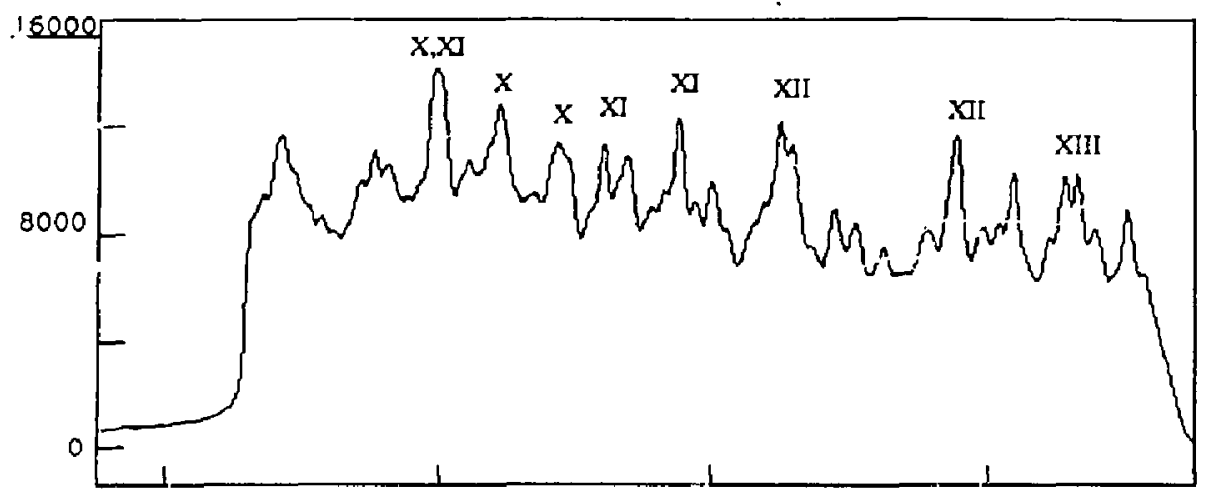

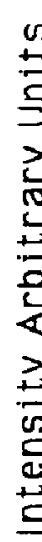

b) $2 \mathrm{~mm}$ above target surface
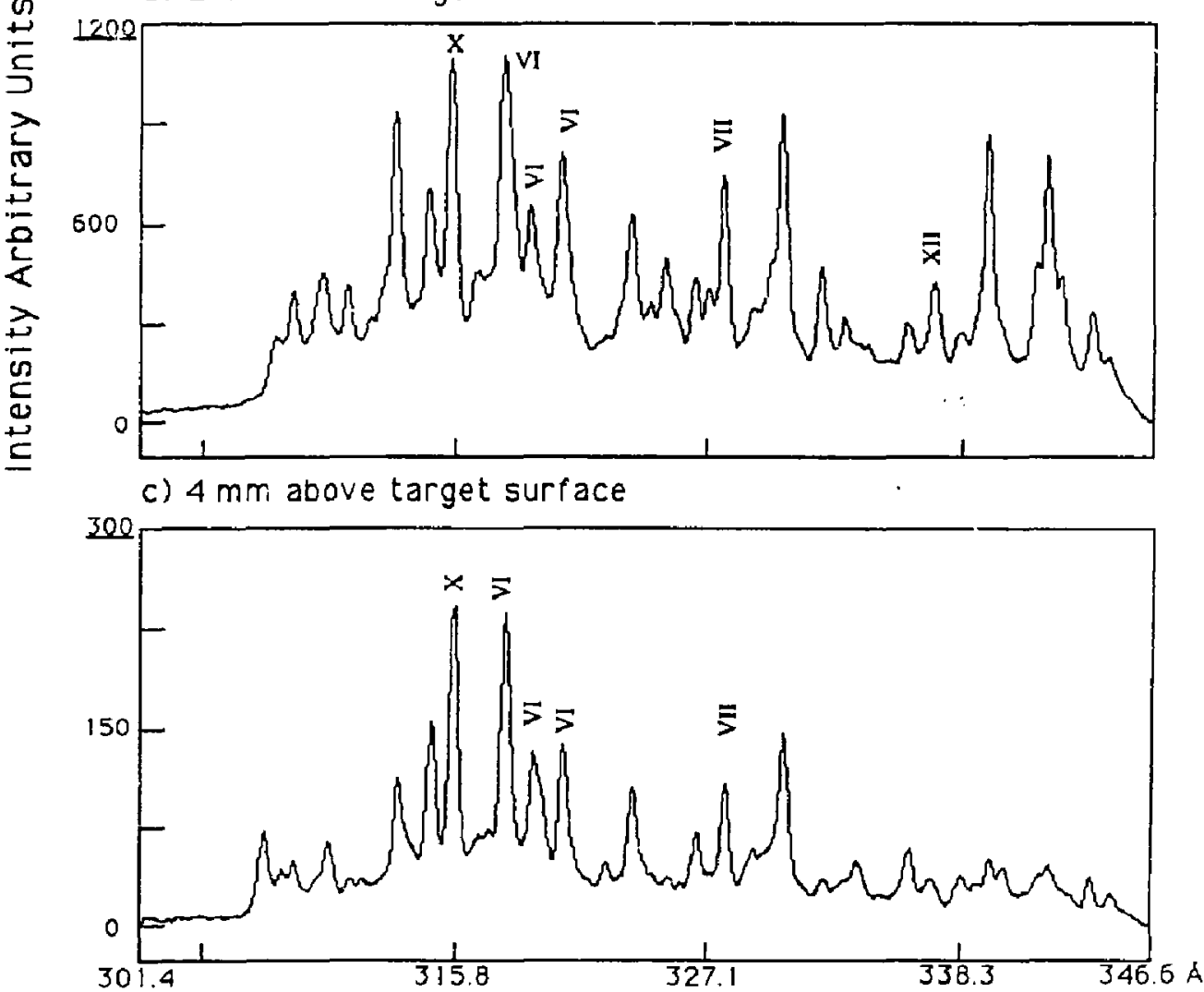

Fig. 11 
a) At target surface
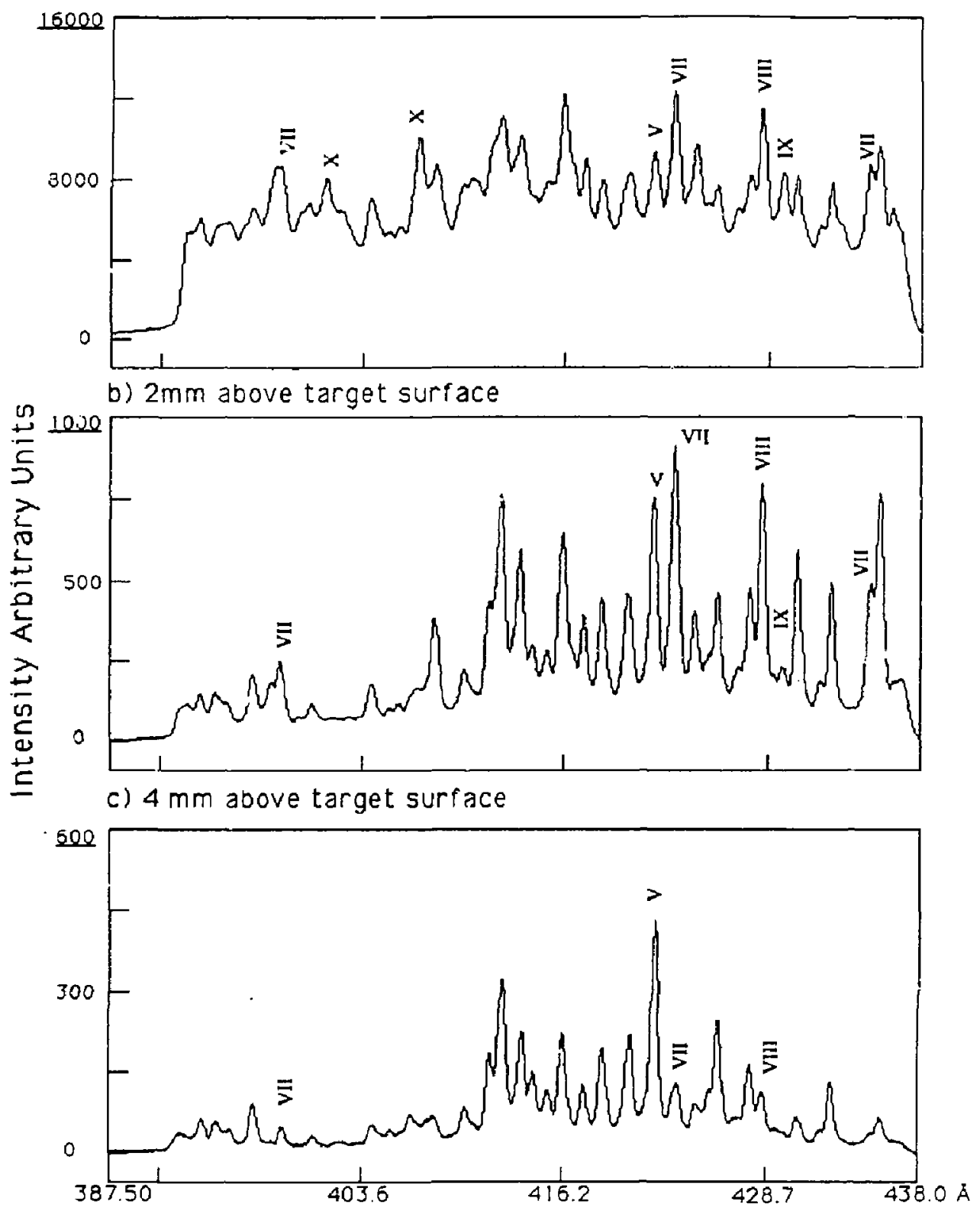

Fig. 12 
a) At target surface

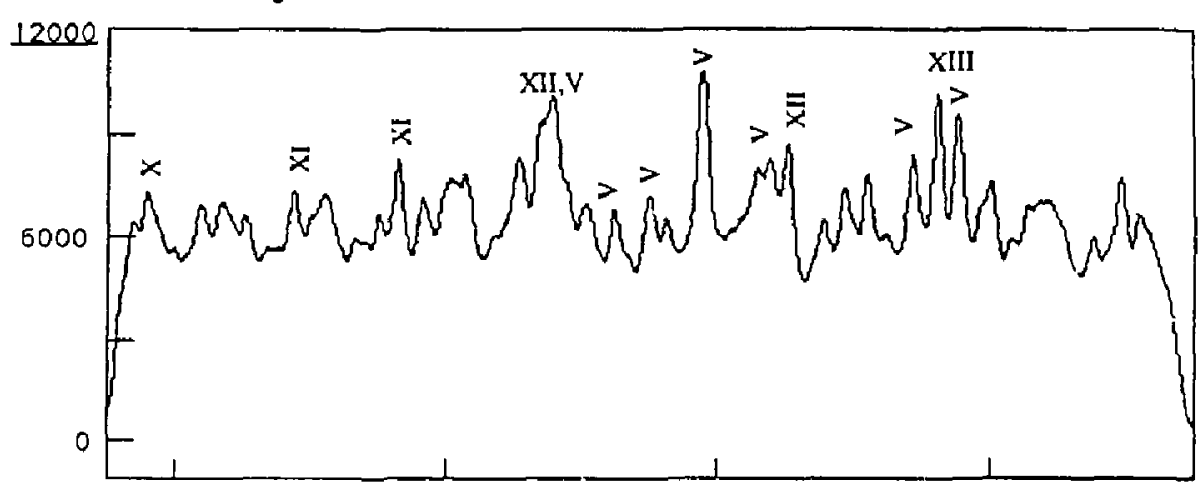

b) $2 \mathrm{~mm}$ above target surface

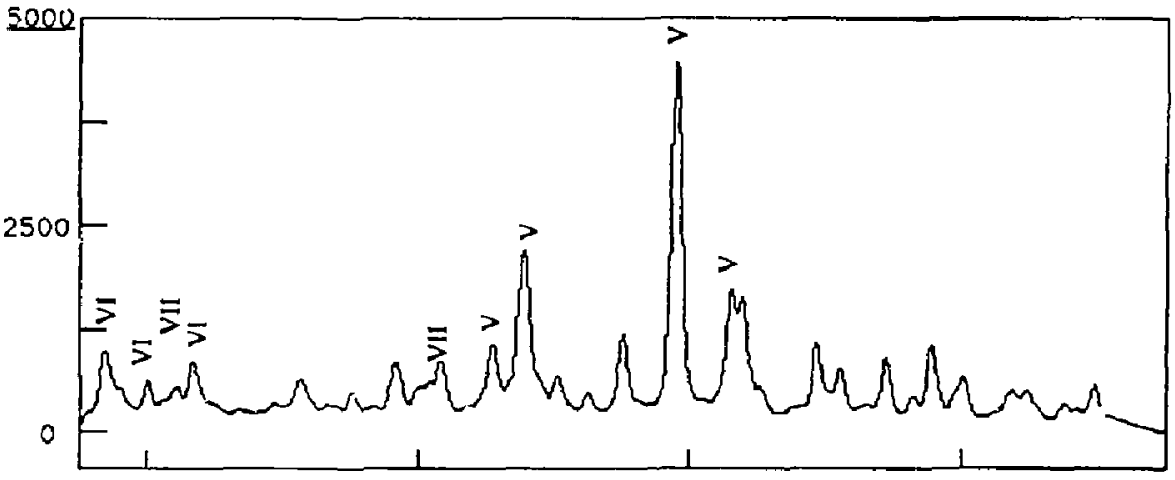

c) $4 \mathrm{~mm}$ above target surface
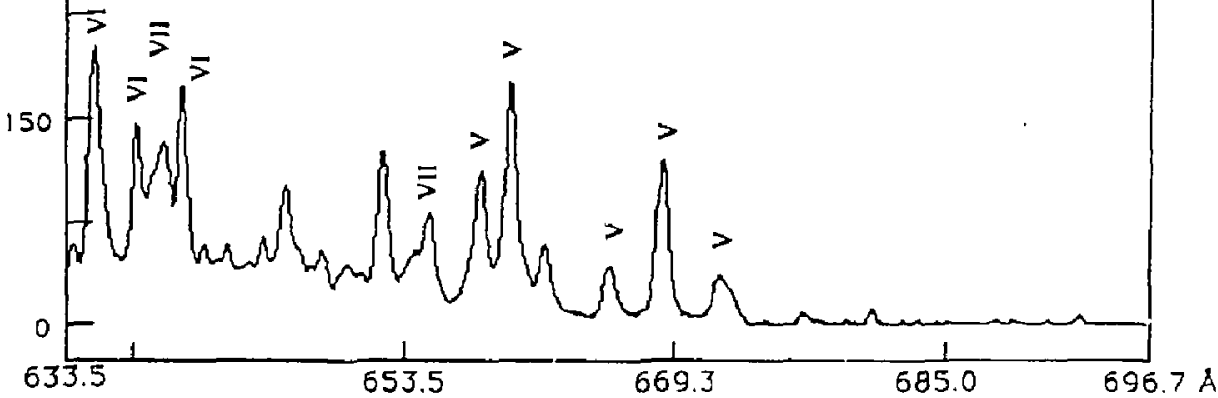

Fig. 13 


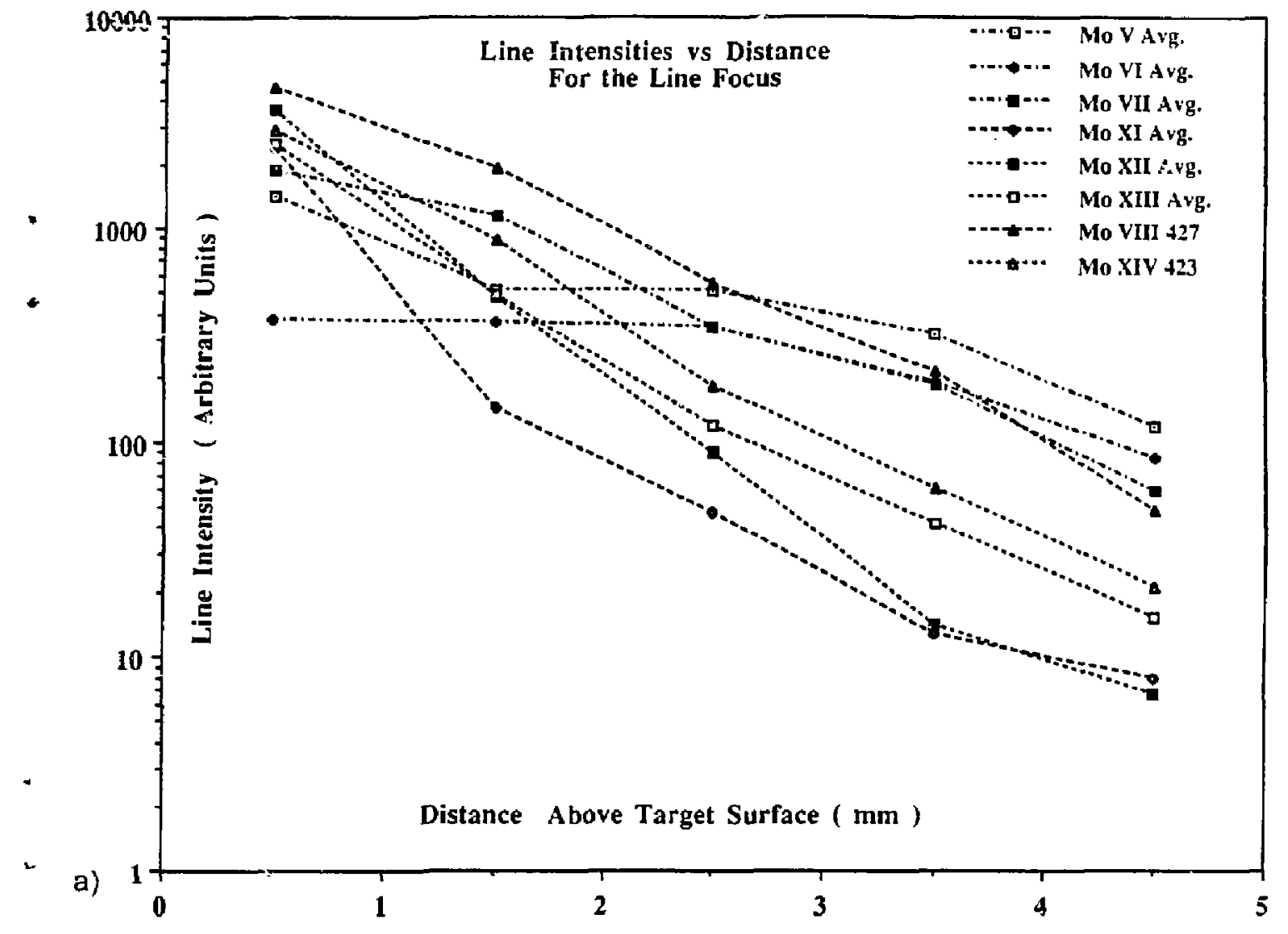

Background Intensity vs Distance for the Line Focus

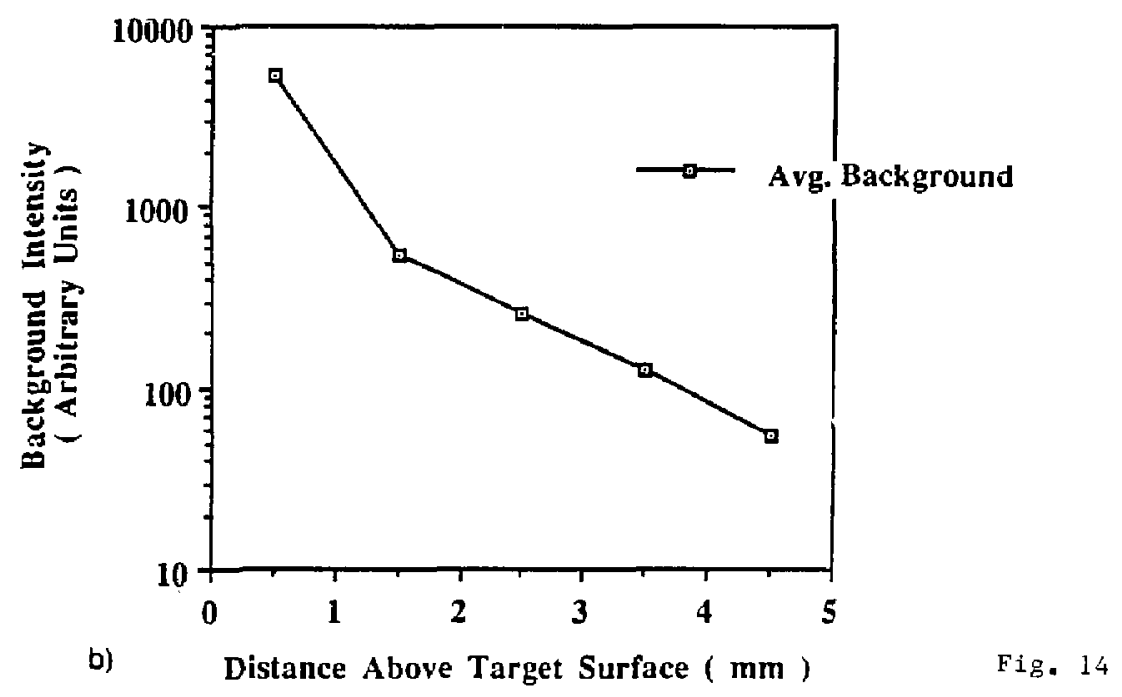


Dr. F. Paoloni, Unir ol Wollonçong, AUSTRALIA

Prof. M.H. Brennan, Univ. ol Sydney, AUSTRALIA

Plasma Research Lab., Australian Nat Univ., AUSTRALIA

Prol. I.R. Jones. F'inders Univ, AUSTRALIA

Prot. F. Cap, Inst tor Theoretical Physics, AUSTrIA

Prot. M. Heindler, Institut fur Theoretisctie Physik. AUSTRIA

Prof. M. Goossens, Astronomisch Instituet, BELGIUM

Ecole Royale Militaire, Lab. de Phy. Plasmas, BELG!UM

Commisssion-European, DG. XII-Fusion Prog.. BELGIUM

Prof. R. Bouciquje, Pijksuniversiteit Gent, BELGIUM

Dr. P.H. Salanaka, Instinto Fisica. BRAZIL

Instituto De Pesquisas Espaciais-INPE, BRAZIL

Documents Oflier, Alomic Energy of Canada Lid., CANADA

Dr. M.P. Bachiyriski. ĥPB Tochnologies, Ine. CANADA

Dr. H.M. Skarsgard, Univ. of Saskatchewan, CANADA

Prof. J. Teichmann, Univ. of Montreal. CANADA

Prof. S.A. Sreenivasan. UniY. of Calgary. CANADA

Prof. TW. Johnston, INRS-Energie, CANADA

Dr. R. Bolton. Centre canadion de fusion magnétique, CANADA

Dr. C.A. James, Univ of Alberta, CANADA

Dr. P. Lukac, Kemensketro Universzita, CzECHOSLOVAKIA

The Librarian, Culham Laboratory. ENGLAND

Libxary, R61. Futhortord Appleton Laboratory, ENGLAND

Mrs. SA. Hutchinson, JET Library. ENGLAND

P. Mathonen, Univ. of Helsinkj, FINLAND

C. Mouttet, Lab. de Physique des Milieux lonisés. FRANCE

J. Radel, CEN/CAOARACHE - Bat 506, FRANCE

Ms. C. Pinnı, Univ, of loannina, GREECE

Dr. T. Mual, Academy Bibliegraphic Ser., HONG KONG

Preprint Library. Hungarian Academy of Sei., HUNGARY

Dr. B. Das Gupta, Saha Inst. of Nudear Phyșics, INDIA

Dr. P. Kaw, Inst lor Plasma Research, INDIA

Dr. P. Rosenau, israel inst. of Tochnology, ISRAEL

Librarian, International Center for Theo Physics, ITALY

Miss C. De Palc. Associazione EURATOM-ENEA , ITALY

Dr. G Grosso, ispituto di Fisica del Plasma, ITALY

Dr. H. Yamato. Toshiba Res Devel Center, JAPAN

Prot. 1. Kawakami. titemic Energy Res.Inst., JAPAN

Prot. K. Nishikawa, Hisoshima Univ., JAPAN
Director, Japan Atomic Energy Research Inst., JAPAN

Prot. S. Iroh. Kyushu Univ., JAPAN

Oala and Planning Center. Nagoya Univ. JAPAN

Prol. S. Taraka, Kyoto Un: , JAPAN

Library. Kyoto Univ., JAPAN

Prot. N. Inove. Univ. of Tokyo. JAPAN

5. Mori, Tochnical Advisor, JAERI, JAPAN

O. Mitarai, Kumamoto inut. of Technology, JAPAN

H. Jeong, Korea Advanced Energy Fesearch Inst., KOREA

Prol. C.I. Choi, The Korea Ady. Inst. of Sa. Toch. KOREA

Prol, 8.S. Liloy. Univ. of Waikalo, NEW ZEALAND

Inst. of Plasma Physics, PEOPLE'S REPUELIC OF CHINA

Librarian, Inst. of Physics, PEOPLE'S REPUBLIC OF CHINA Litrary, Tsinghua Univ., PEOFLE'S REPU日LIC OF CHINA

Z. Li. S.W. Inst Pi jsics. PEOPLE'S REPUBLIC OF CHINA Prof. J.A.C. Cabral, Instituto Suparior Tecnico, PORTUGAL

Dr. O. Petrus, AL I CUZA Univ., ROMANIA

Dr. J. to Villiers, Fusion Studies, AEC. 5. AFRICA

Prot, M.A. Hellberg, Univ. of NabaJ, S. AFRICA

C.I.E.M.A.T, Fusion Division Library, SPAIN

Dr. L Stantho, Univ. of UMEA, SWEDEN

Library. Rayal Inst. of Technology, SWEDEN

Prof. H. Wilheimson, Chalmers Univ. of Tech., SWEDEN

Contro Phys. Des Plasmas, Ecolo Polytoch, SWITZERLAND

Bibliotheak, Inst. Voor Plasme-Fysica, THE NETHERLANDS

M. Durgur Vice Chairman, Middle East Tech. Univ., TURKEY

Dr. D.D. Ryutov, Siberian Branch of Academy of Sci.. USSR

Dr. G.A. Eliseev, Kurchatov Inst., USSA

Librarian, The Uly.SSR Academy of Sciences, USSR

Dr. LM. Kourizhnykh, Inst. of Genetal Physics, USSR

Kemforschungsaniage GmbH. Zentralbibliothek, W. GERMANY

Bibliothek, inst. Für Plasmajorschung. W. GEAMANY

Prof. K. Schinder, Ruhr-Universiat Bochum, W. GERMANY

Dr. F, Wagner, (ASDEX), Max-Planck-Institut, W. GERMANY

Librarian, Max-Planck-Insjitut, W. GERMANY

Prot. R.K Janev, Inst. of Physics, YUGOSLAVIA 